\title{
IPTEK BAGI MASYARAKAT : PEMBERDAYAAN MASYARAKAT DALAM PENATALAKSANAAN HIPERTENSI PADA LANSIA UNTUK MENCIPTAKAN LANSIA SEHAT DAN MANDIRI (Pemanfaatan Rebusan Air Daun Syzgium Polyanthum)
}

\author{
Ferasinta, S.Kep., Ners., M.Kep ${ }^{1}$, Lussyefrida Yanti $^{2}$, Eva Oktavidiati ${ }^{3}$, Panzilion ${ }^{4}$ \\ ${ }^{1,2,4}$ Program Studi Ilmu Keperawatan \\ ${ }^{3}$ Program Studi Agroteknologi \\ Fakultas Ilmu Kesehatan Universitas Muhammadiyah Bengkulu \\ Correponding author : ferasinta@umb.ac.id
}

\begin{abstract}
ABSTRAK
Hipertensi merupakan faktor yang meningkatkan resiko terjadinya penyakit kardiovaskuler seperti gagal ginjal, stroke bahkan kematian. Melihat kompleknya permasalahan tekanan darah tinggi atau hipertensi sehingga perlunya pengontrolan tekanan darah teruatama pada lansia yang mempunyai riwayat tekanan darah tinggi.

Upaya yang dapat dilakukan untuk menurunkan angka kejadian hipertensi diantaranya melakukan kegiatan pengukuran tekanan darah atau pemeriksaan kesehatan, penyuluhan mengenai penyakit hipertensi dan pengobatan atau penanganan untuk menurunkan tekanan darah salah satunya rebusan daun salam (Syzygium Polyanthum). Sasaran pada pelaksanaan penyuluhan kesehatan ini adalah lansia dan kader-kader di desa Babakan Bogor Kab.Kepahiang. Sebelum penyuluhan dilakukan pemeriksaan tekanan darah dan dilanjutkan dengan pemaparan materi menggunakan Proyeksi LCD dan diskusi dengan peserta penyuluhan.

Hasil dari pelaksanaan pemberdayaan masyarakat dengan penyuluhan penatalaksanaan penyakit hipertensi pada lansia menggunakan rebusan daun salam yaitu peserta sangat antusias serta mengikuti arahan dari penyuluh secara rutin dan pihak kader menyatakan bahwa lansia sudah rutin memeriksakan tekanan darahnya saat posyandu lansia.
\end{abstract}

Kata Kunci : Tekanan Darah, Daun Salam

\section{PENDAHULUAN}

Hipertensi merupakan salah satu penyebab kematian dini diseluruh dunia sehingga disebut sebagai "silent killer", karena seringkali penderita Hipertensi tidak merasakan gejala apapun. Diseluruh dunia, Hampir satu miliar orang meninggal setiap tahunnya, dua pertiga dari penderita Hipertensi terdapat di Negara berkembang dan diperkirakan pada tahun 2025 akan ada 1,56 miliar orang dewasa yang mengalami hipertensi. Hipertensi dapat membunuh hampir 8 juta orang setiap tahun dan di
Asia Tenggara hampir 1,5 juta orang dan atau sepertiga penduduk mengalami Hipertensi (WHO, 2011).

Hipertensi dapat menyerang hampir semua golongan masyarakat diseluruh dunia, dimana jumlah masyarakat yang mengalami hipertensi semakin bertambah dari tahun ke tahun. Di Amerika, menurut National Health and Nutrition Examination Survey III (NHNES III) paling sedikit $30 \%$ penderita hipertensi sebagian besar tidak menyadari kondisi mereka, dan hanya $31 \%$ penderita yang diobati mencapai target tekanan darah yang 
dinginkan dibawah 140/90 mmHg. Berdasarkan penelitian dari American Hypertension Association (2006) hanya $68 \%$ penderita hipertensi tahu bahwa mereka menderita hipertensi dan sisanya sama sekali tidak tahu bahwa mereka menderita hipertensi. Diperkirakan $30 \%$ penduduk Amerika $( \pm 50$ juta jiwa) menderita tekanan darah tinggi.National Health and Nutrition Examination Survey (NHNES) menyatakan bahwa insiden kasus 107 penderita Hipertensi pada tahun 20102012 di Amerika adalah sekitar 39-51\%, yang berarti bahwa terdapat 58-65 juta orang menderita hipertensi dan itu menunjukkan terjadi peningkatan 15 juta penderita dari data NHNES III (Triyanto, 2014).

Prevalensi Hipertensi pada populasi yang berpengahasilan rendah dan menengah serta di Negara-Negara yang memiliki Sistem Kesehatan yang tergolong lemah.Karena sering tidak memiliki gejala awal, maka penderita Hipertensi secara umum tidak mengetahui bahwa mereka mengalami Hipertensi dan bagi mereka yang telah didiagnosis mungkin tidak memiliki akses terhadap pengobatan dan tidak dapat mengontrol penyakit secara jangka panjang (WHO, 2013). Penderita hipertensi juga menyerang Thailand sebesar $17 \%$ dari total penduduk, Vietnam $34,6 \%$, Singapura 24,9\%, Malaysia 29,9\%. Kasus Hipertensi terus bertambah terutama di Negara-Negara berkembang dan persentasenya sekitar $80 \%$. Tahun 2013, kejadian hipertensi pada usia 18 tahun ke atas di Indonesia yang didapat melalui jawaban pernah didagnosis oleh tenaga kesehatan 9,4\%, sedang minum obat 9,5 $\%$, terdapat $0,1 \%$ penduduk yang minum obat sendiri meskipun tidak pernah didiagnosis hipertensi oleh tenaga kesehatan (Susilo \& Wulandari, 2011).

Prevalensi hipertensi di Indonesia yang didapat melalui pengukuran pada umur $\geq 18$ tahun sebesar 25,8 persen, tertinggi di Bangka Belitung (30,9\%), diikuti Kalimantan Selatan (30,8\%),
Kalimantan Timur $(29,6 \%)$ dan Jawa Barat $(29,4 \%)$. Prevalensi hipertensi di Indonesia yang didapat melalui kuesioner terdiagnosis tenaga kesehatan sebesar 9,4 persen, yang didiagnosis tenaga kesehatan atau sedang minum obat sebesar 9,5 persen. Jadi, ada 0,1persen yang minum obat sendiri. Responden yang mempunyai tekanan darah normal tetapi sedang minum obat hipertensi sebesar 0.7 persen. Jadi prevalensi hipertensi di Indonesia sebesar 26,5 persen $(25,8 \%+0,7 \%)$. Prevalensi kejadian hipertensi di provinsi Bengkulu berdasarkan hasil pengukuran langsung sejumlah (21,6 \%) (Riskerdas, 2013). Kasus hipertensi tahun 2015 di Provinsi Bengkulu untuk masing-masing Kabupaten kejadian tertinggi adalah kabupaten Rejang Lebong (78\%), Bengkulu Utara $(75,1)$, Bengkulu Tengah $(29,8)$.

Penyakit hipertensi disederhanakan dengan sebutan tekanan darah tinggi level $140 \mathrm{~mm} \mathrm{Hg}$ atau lebih dan tekanan darah diastolik pada level $90 \mathrm{~mm} \mathrm{Hg}$ atau lebih (Black \& Hawk, 2014). Hipertensi dapat memberikan kontribusi bagi kejadian penyakit jantung, gagal ginjal, stroke, kematian prematur dan cacat.Faktor pemicu terjadinya hipertensi diantaranya adalah faktor genetik, jenis kelamin, usia, tingkat stres, obesitas, dan konsumsi garam serta alkohol. Hipertensi merupakan faktor yang meningkatkan resiko terjadinya penyakit kardiovaskuler, gagal ginjal, stroke dan kematian. Melihat kompleknya permasalahan tekanan darah tinggi atau hipertensi, dapat disimpulkan bahwa apabila tidak dilakukan pengobatan dan pengontrolan tekanan darah maka akan dapat menimbulkan komplikasi pada tubuh (Suidah, 2011).

Upaya yang dapat dilakukan untuk menurunkan angka kejadian hipertensi diantaranya melakukan kegiatan pengukuran tekanan darah atau pemeriksaan kesehatan, penyuluhan mengenai penyakit hipertensi dan pengobatan atau penanganan untuk menurunkan tekanan darah. Upaya lain 
yang dapat dilakukan untuk mencegah hipertensi antara lain monitoring tekanan darah secara teratur, program hidup sehat tanpa asap rokok, diet sehat dengan kalori yang seimbang melalui konsumsi tinggi serat, rendah lemak dan rendah garam.

Salah satu bentuk kegiatan yang dapat dilakukan oleh tenaga kesehatan adalah untuk pengontrolan tekanan darah dengan memberikan pendidikan kesehatan kepada penderita hipertensi (Susanti, dkk. 2012) Pendidikan kesehatan merupakan suatu proses yang direncanakan untuk mempengaruhi atau mengajak orang lain, baik individu, kelompok atau masyarakat agar melaksanakan perilaku hidup sehat (Nursalam \& Efendi, 2008). Hal ini sejalan dengan hasil penelitian Susanti, dkk (2012) dimana ada pengaruh antara pendidikan kesehatan tentang hipertensi terhadap sikap dalam mengelola hipertensi.

Salah satu tindakan non farmakologi yang dapat dilakukan untuk menurunkan tekanan darah pada penderita hipertensi adalah rebusan daun salam.

\section{METODE KEGIATAN}

Kegiatan ini dilaksanakan di Desa Babakan Bogor Kecamatan Kabawetan Kabupaten Kepahiang mulai dari tanggal 24 Juli 2019 sampai dengan 5 september 2019 yang diikuti oleh pihak posbindu, karang taruna, tokoh masyarakat, tokoh agama, masyarakat desa setempat serta aparatur desa Babakan Bogor Kecamatan Kabawetan Kabupaten Kepahiang.

Metode pelaksanaan kegiatan ini adalah dengan memberikan pendidikan kesehatan atau penyuluhan tentang penyakit hipertensi mulai dari definisi, etiologi, manifestasi klinis, komplikasi, pencegahan dan penatalaksanaan serta melakukan pemeriksaan kesehatan, pelatihan serta pendampingan. Pendidikan kesehatan atau penyuluhan dilakukan untuk menambah wawasan masyarakat tentang apa itu hipertensi, penyebabnya, tanda dan gejala, pemeriksaan penunjang komplikasi, pencegahan dan penataklaksanaan baik farmakologi maupun non farmakologi dari penyakit hipertensi serta penyuluhan tentang apa itu tanaman daun salam.

Kegiatan pemeriksaan kesehatan dilakukan untuk mengetahui dan mengontrol tekanan darah masyarakat yang beresiko mengalami penyakit hipertensi dengan melakukan pemeriksaan dini seperti pemeriksaan vital sign, gula darah. Setelah itu masyarakat yang berisiko akan diberikan pelatihan untuk melakukan senam hipertensi dan mencegah penyakit hipertensi dengan membuat obat-obatan nonfarmakologi untuk pengontrolan hipertensi seperti rebusan daun salam.

Kegiatan selanjutnya adalah dari tahapan di atas, petugas kesehatan akan melakukan pendampingan pada masyarakat yang menderita hipertensi supaya dapat mengontrol tekanan darahnya dan melakukan penatalaksanaan non farmakologi dengan benar serta. Diharapkan penyuluh pertanian setempat akan melakukan pendampingan cara pemanfaatan pekarangan rumah untuk budidaya penanaman tanaman daun salam.

\section{HASIL DAN PEMBAHASAN}

a. Kegiatan Lokakarya Awal

Diminggu pertama dilakukan Pelaksanaan lokakarya awal dilaksanakan pada pukul 20.00 WIB sampai dengan selesai yang dilaksanakan di Balai Desa Babakan Bogor. Kegiatan lokakarya awal ini dilaksanakan pada tanggal 26 Agustus 2019 diikuti oleh 38 oang terdiri dari karang taruna, masyarakat, perangkat desaBabakan Bogor Kecamatan Kabawetan Kabupaten Kepahiang dan tim pengabdian. Harapan dari kegiatan ini adalah tercapainya tujuan lokakarya awal dengan baik, agar masyarakat sekitar dapat menerima keberadaan tim Pengabdian dan mengikuti setiap program kerja yang akan dilakukan oleh tim pengabdian di desa 


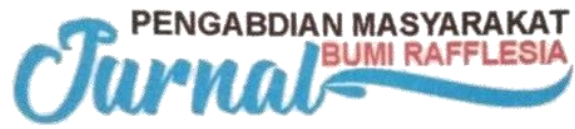

tersebut mulai dari kegiatan pengkajian penyakit hipertensi, pendidikan kesehatan tentang hipertensi, pelatihan pembuatan terapi nonfarmakologi dengan memanfaatkan tanaman daun salam.

Berikut adalah dokumentasi kegiatan sebelum dilaksanakanya kegiatan lokakarya awal :

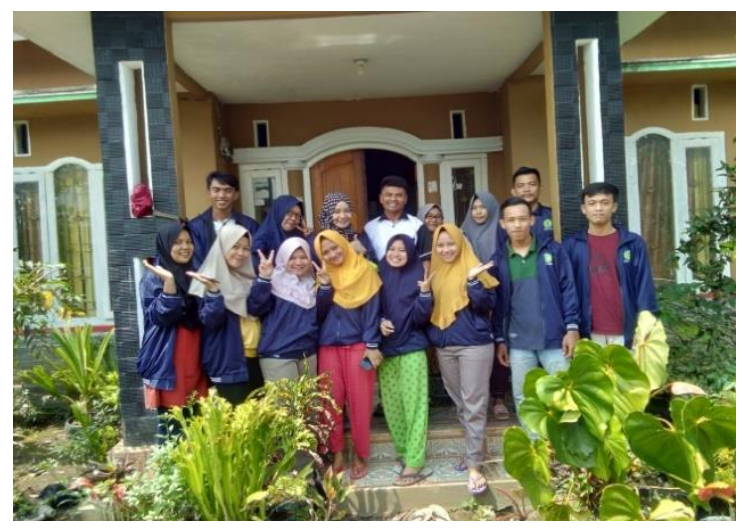

Dokumentasi Serah Terima Tim

Pengabdian Kepada Kepala Desa

Babakan Bogor Kecamatan

KabawetanKabupaten Kepahiang

b. Kegiatan Pengkajian Hipertensi

Kegiatan pengkajian penyakit Hipertensi dilakukan pada Lansia di Balai desa Serumbung. setelah kegiatan tersebut dilanjutkan dengan kontrak waktu untuk pelaksanaan pendidikan kesehatan tentang hipertensi yang akan diberikan olehtim pengabdian. Kegiatan ini memiliki tema Peningkatan kemampuan mahasiswa dalam melakukan pengkajian hipertensi pada lansia. Pelaksanaan kegiatan pengkajian dilakukan tim pengabdian pada tanggal 25 Agustus 2019 s/d 30 Agustus 2019 dan disetujui oleh Kepala Desa Babakan Bogor. Hasil dari kegiatan pengkajian hipertensi ini pada lansia di Balai Desa Babakan Bogor didapatkan 38 lansia menderita penyakit Hipertensi serta hasil wawancara dengan lansia yang menderita hipertensi tersebut didapatkan bahwasanya pengetahuan lansia tentang hipertensi sangat kurang, lansia juga tidak memahami tentang pengontrolan tekanan darah baik secara farmakologi maupun non farmakologi.

\section{c. Kegiatan Senam Hipertensi}

Pelaksanaan kegiatan senam hipertensi dibuka pada pukul 08.00 WIB s/d selesai oleh Tim Pengabdian dan lansia di Balai desa Babakan Bogor Kegiatan senam hipertensi dilaksanakan pada tanggal 10 Agustus 2019 dan 30 Agustus 2019. Pada hari pertama dan kedua masing-masing diikuti oleh lansia 38 orang serta pengurus posbindu serta para mahasiswa yang dilaksanakan secara aktif. Hasil dari kegiatan ini semua lansia aktif dalam mengikuti kegiatan senam baik yang dilakukan pada hari ke satu maupun kedua. Pihak posbindu akan memfasilitasi kegiatan senam hipertensi agar dilakukan sebagai kegiatan senam rutin setiap adanya jadwal posyandu lansia di Desa Babakan Bogor Kecamatan Kabawetan Kabupaten Kepahiang. Lansia juga dapat memahami dengan baik setiap gerakan-gerakan senam yang sudah diajarkan oleh Tim Pengabdian Masyarakat.

Berikut adalah dokumentasi kegiatan senam hipertensi bersama lansia.

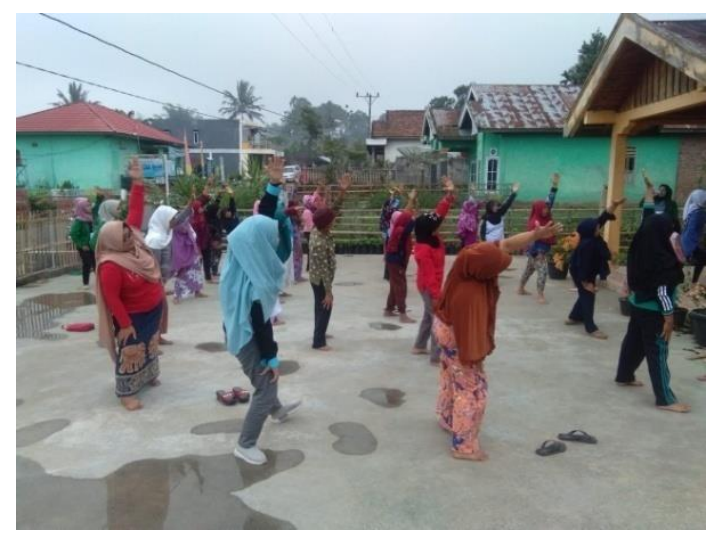

Dokumentasi Kegiatan Senam Hipertensi yang dipandu Oleh Tim Pengabdian Masyarakat

d. Kegiatan Pendidikan Kesehatan Tentang Hipertensi 


\section{Currnalls}

Pelaksanaan kegiatan pendidikan kesehatan tentang hipertensi dibuka pada pukul 09.00 WIB sampai dengan selesai yang dimulai dari kata sambutan Kepala Desa Babakan Bogor Kecamatan Kabawetan Kabupaten Kepahiang, dilanjutkan penyampaian materi pendidikan kesehatan tentang hipertensi dengan pemateri :Ns. Ferasinta, S.Kep.,M.Kep selaku ketua pelaksana kegiatan pengabdian masyarakat di Desa Babakan Bogor Kecamatan Kabawetan Kabupaten Kepahiang. Kegiatan pendidikan kesehatan tentang hipertensi diikuti oleh 38 lansia, anggota posbindu dari Puskesmas Kabawetan serta mahasiswa dan Tim Pengabdian Masyarakat. Hasil dari kegiatan ini lansia mampu memahami tentang hipertensi mulai dari definisi, etiologi, manifestasi klinis, pemeriksaan diagnostik, pemeriksaan penunjang komplikasi, pencegahan dan penatalaksanaan untuk menurunkan tekanan darah dari penderita hipertensi dengan baik dan benar baik penatalaksanaan farmakologi maupun non farmakologi.

Berikut dokumentasi kegiatan mulai dari kata sambutan, penyampaian materi dan sesi tanya jawab antara tim pengabdian dan lansia di Desa Babakan Bogor Kecamatan Kabawetan Kabupaten Kepahiang :

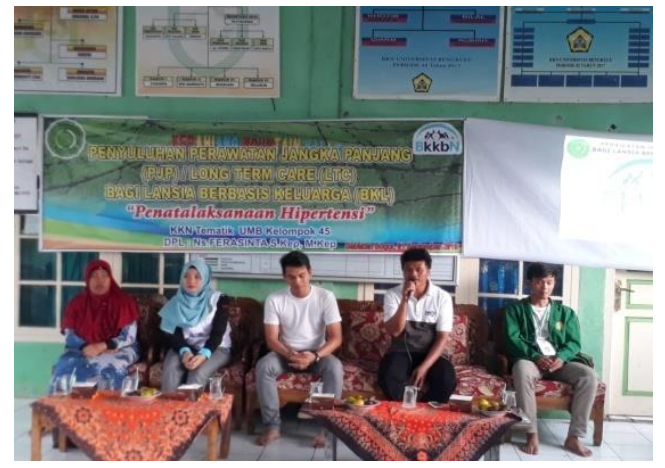

Dokumentasi Kata Sambutan dari Kepala Desa Babakan Bogor Sebelum kegiatan penyuluhan dimulai

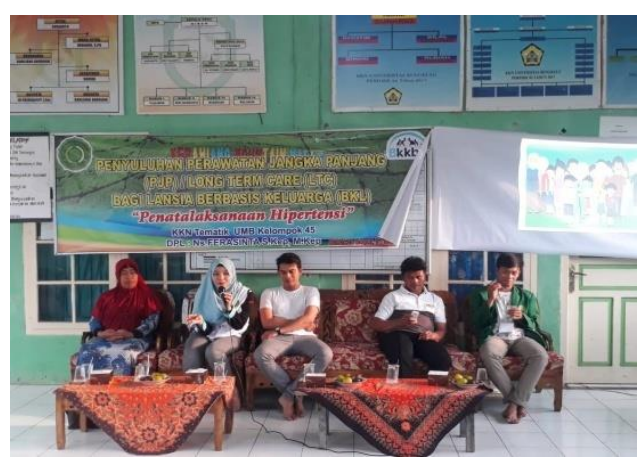

Dokumentasi Pendidikan kesehatan tentang hipertensi dari Tim Pengabdian

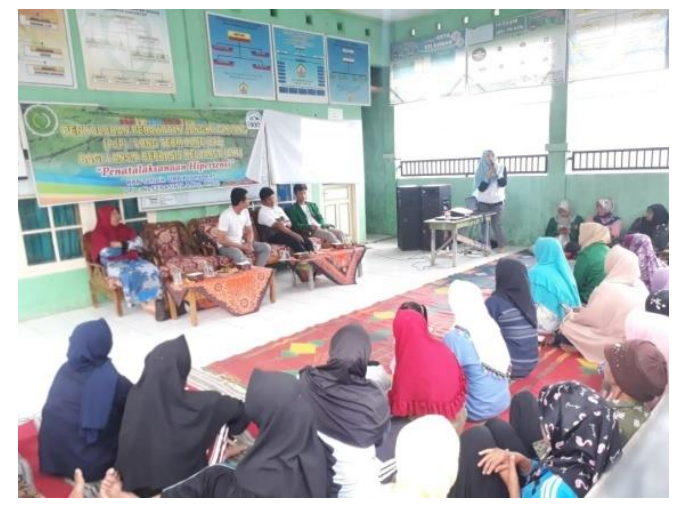

Dokumentasi Pendidikan kesehatan tentang hipertensi dari Tim Pengabdian

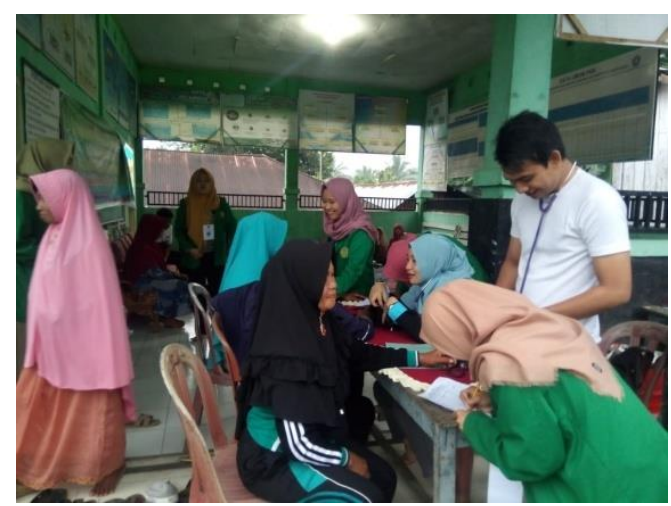

Dokumentasi Pemeriksaan Tekanan darah lansia

e.Kegiatan Lokakarya Akhir

Kegiatan lokakarya akhir dilaksanakan pada pukul 14.00 WIB sampai dengan selesai yang dilaksanakan oleh Tim Pengabdian Masyarakat dimana pelaksanaan kegiatan lokakarya akhir 
dilakukan di Balai desa Babakan Bogor. Kegiatan ini dilaksanaan pada tanggal 1 september 2019yang diikuti oleh 38 orang yang terdiri dari karang taruna, tokoh masyarakat, tokoh agama, warga desa serta aparatur desa Babakan Bogor Kecamatan Kabawetan Kabupaten Kepahiang. Kegiatan ini menyampaikan terkait seluruh program kerja yang sudah dilakukan tim Pengabdian Masyarakat dimulai dari kegiatan pengkajian penyakit hipertensi, pendidikan kesehatan tentang hipertensi. Harapan masyarakat desa Babakan Bogor agar kedepanya kegiatan-kegiatan seperti ini dapat dilaksanakan lagi dengan meningkatan kuantitas dan kualitas pelaksanaan pengabdian masyarakat yang sangat bermanfaat untuk masyarakat desa Babakan Bogor Kecamatan Kabawetan Kabupaten Kepahiang.

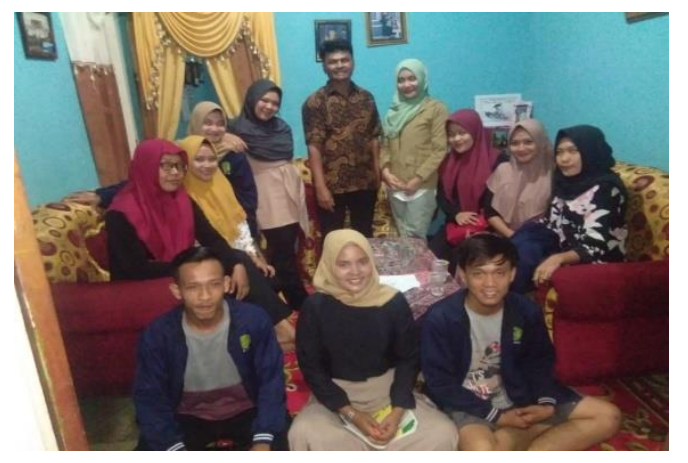

Dokumentasi Penarikan mahasiswa kepada Kepala Desa Babakan Bogor Kecamatan Kabawetan Kabupaten Kepahiang

\section{PENUTUP}

\section{Kesimpulan}

Hasil dari pengabdian masyarakat ini adalah:

1. Kegiatan lokakarya awal diikuti oleh karang taruna, perangkat desa dan tim pengabdian masyarakat di Balai Desa Babakan Bogor Kecamatan Kabawetan Kabupaten Kepahiang dimana menyampaikan program kerja yang akan dilakukan mulai dari pengkajian hipertensi, pendidikan kesehatan tentang hipertensi, senam hipertensi, penatalaksanaan non farmakologis dari penyakit hipertensi, penyuluhan pembudidayaan tanaman salam.

2. Kegiatan pengkajian hipertensi dilaksanakan selama 3 tiga hari dimana didapatkan 38 lansia di desa Babakan Bogor Kecamatan Kabawetan Kabupaten Kepahiang yang menderita penyakit hipertensi dan tidak mengetahui tentang apa itu penyakit hipertensi serta cara penatalaksanaanya baik farmakologi maupun non farmakologi.

3. Kegiatan senam hipertensi dilaksanakan selama dua hari yang diikuti oleh 38 orang lansia, dan pengurus posbindu Puskesmas Kabawetan yang dilakukan secara aktif dan menjadi masukan untuk dilakukan secara rutin ketika pelaksanaan kegiatan posyandu lansia.

4. Kegiatan pendidikan kesehatan tentang hipertensi diikuti Tim Pengabdian, Aparatur desa Babakan Bogor, Tim Posbindu serta 38 orang lansia desa Babakan Bogor Kabupaten Kepahiang yang dilakukan di balai desa dimana kegiatan ini menambah pengetahuan lansia tentang definisi dari penyakit hipertensi, penyebab, manifestasi klinis, pemeriksaan diagnosti, pemeriksaan penunjang, komplikasi serta penatalaksanaan farmakologi dan non farmakologi.

5. Kegiatan lokakarya akhir dihadiri oleh karang taruna, tokoh masyarakat, tokoh agama, aparatur desa Babakan Bogor Kecamatan Kabawetan Kabupaten Kepahiang yang dilakukan di balai desa tentang pelaporan program kerja yang sudah dilakukan tim pengabdian masyarakat. 
Saran

Kegiatan pemanfaatan tanaman daun salam dipekarangan rumah untuk pengontrolan tekanan darah dapat dilakukan lebih optimal lagi jika melibatkan instansi terkait seperti dinas Kesehatan Kabupaten dan Dinas Pertanian. Ketersediaan obat-obatan yang berada di puskesmas diharapkan dapat ditingkatkan kembali agar ketika ada klien yang melakukan pemeriksaan kesehatan klien tersebut dapat mendapatkan pegobatan secara langsung sesuai standar operasional prosedur. Serta diharapkan kegiatan seperti ini dapat menjadi kegiatan rutin di Desa Babakan Bogor Kecamatan Kabawetan Kabupaten Kepahiang dengan melibatkan Puskesmas yang mewadahi desa tersebut. Intervensi non farmakologi yang telah diajarkan diharapkan dapat diterapkan dikehidupan sehari-hari masyarakat Desa Babakan Bogor Kecamatan Kabawetan Kabupaten Kepahiang.

\section{DAFTAR PUSTAKA}

Ardiansyah, Muhamad. (2012). Medikal bedah. Yogyakarta: Diva Press.

Blacks, M.J. \& Hawk, H.J. (2014). Keperawatan medikal bedah: manajemen klinis untuk hasil yang diharapkan. (Edisi 8). Jakarta: Salemba Medika.

Dinkes Provinsi Bengkulu. (2016). Profil Dinas Kesehatan Provinsi Bengkulu 2015.

Gunawan, G. Suherman. Ayesha. I. (2016). Pemanfaatan lahan pekarangan di kawasan penyangga tnuk untuk menopang pangan rumah tangga.UNES Journal Of Community Service. ISSN Print : 2528-5572|ISSN Online : 2528$6846 . \quad$ Diakses dari http://journal.univ- ekasaktipdg.ac.id/index.php/lppm/a rticle/view/59.

Nursalam, \& Effendi, F. (2008). Pendidikan dalam keperawatan. Jakarta: Salemba Medika.

Riskesdas. (2013). Badan penelitian dan pengembangan kesehatan kementerian kesehatan ri. Jakarta. Diakses dari http://www.depkes.go.id/resources/ download/general/Hasil\%20Riskes das\%202013.pdf.

Sakinah, S. Azhari,K.H. (2018). Pengaruh rebusan daun seledri terhadap penurunan tekanan darah pada pasien hipertensi di wilayah kerja puskesmaspangkajene kabupaten sidrap. Jurnal Ilmiah Kesehatan Diagnosis Volume 12 Nomor 3 Tahun 2018. eISSN : 2302-2531. Diakses dari http://ejournal.stikesnh.ac.id/index. php/jikd/article/view/317.

Susanti, T.M. Suryani, M. Shobirun. (2012). Pengaruh pendidikan kesehatan tentang hipertensi terhadap pengetahuan dan sikap mengelola hipertensi di puskesmas pandanaran semarang. Karya Ilmiah S1 Keperawatan. Diakses dari http://182.253.197.100/ejournal/index.php/ilmukeperawatan /article/view/66/105.

Susilo, Y dan Wulandari, A. (2011).Cara jitu mengatasi hipertensi. Yogyakarta : Andi.

Triyanto, E. (2014). Pelayanan keperawatan bagi penderita hipertensi secara terpadu. Graha Ilmu: Yogyakarta.

Wibowo, A.M. (2010). Pengaruh pemberian jus mentimun terhadap 
penurunan tekanan darah sistolik dan diastolik penderita hipertensi esensial pada lansia di pstw budi luhur yogyakarta. Yogyakarta. Skripsi.

WHO. (2011). Hypertension and fact sheet. Regional office for SouthEast Asia: Department of Sustainable Development and Healthy Environments.

WHO. (2013). A global brief on hypertension. Regional office for South-East Asia: Department of Sustainable Development and Healthy Environments. 